\title{
Models of "joint consumption economy" in agro-industrial sector: approaches to development
}

\author{
Elena Platonova ${ }^{1 *}$, Olga Fedotova ${ }^{2}$, Tianhui Zhang ${ }^{1}$, Elena Kuznetsova ${ }^{1}$, and Mark \\ Musarskiy ${ }^{1}$ \\ ${ }^{1}$ Moscow Pedagogical State University, Malaya Pirogovskaya str., 1/1, Moscow, 119571, Russia \\ ${ }^{2}$ Don State Technical University, Gagarina sq., 1, Rostov-on-Don, 344003, Russia
}

\begin{abstract}
The aim of the article is to analyze the models of the joint consumption economy from the point of view of finding the applicability of such models in the agro-industrial sector of the economy as tools to increase its efficiency and competitiveness. The authors have described the models of joint consumption economy based on the analysis of the differences between the definitions of "joint consumption economy" and "sharing economy» in the works of researchers. Authors allocate the assets-based, service and financial models of joint consumption economy. The study shows that in the Russian agro-industrial sector there are certain reserves for increasing its efficiency and competitiveness while creating the favorable conditions by State for the continuation of the implementation of the models of joint consumption economy in the near future. These conditions should become the object of further research, as well as the choice of the most appropriate business models for the domestic agro-industrial sector.
\end{abstract}

\section{Introduction}

Rapid advances in digital technology have had a decisive impact on the emergence of new sectors of the modern economy. The widespread use by households for own needs of the digital on-line technological platforms based on the Internet (hereinafter - DOTP) led to the setting up a new sector that in Western and later in Russian economic science was called the "joint consumption economy" (JCE). The results of the analysis of the international bibliographic database Scopus Elsevier show that JCE as a phenomenon of the digital economy became an object of scientific research in the late 90 s of the last century $[1,2]$.

In the first decade of the 21 st century, consumer concepts of car sharing and flat sharing gained the great popularity among households in the field of the provision of the transport and tourism services in the American, European and eastern economies (Uber, Zipcar, Airbnb, HouseTrip).

Published in 2010, the book by Rachel Botsman and Roo Rogers became a landmark scientific work, which summarizes the main features of the development of JCE at that time

\footnotetext{
${ }^{*}$ Corresponding author: ed.platonova@mpgu.su
} 
[3]. The authors have described the role of a new type of companies that develop DOTP and technologically support of such consumer models as car sharing, exchange of consumer goods, as well as the exchange of unique products, including self-made works of artists and artisans. Since 2010, there has been an increase in international publications devoted to the comprehensive characteristics of JCE and the new directions of its development. Data from the international bibliographic database Scopus Elsevier confirm this fact (Fig. 1).

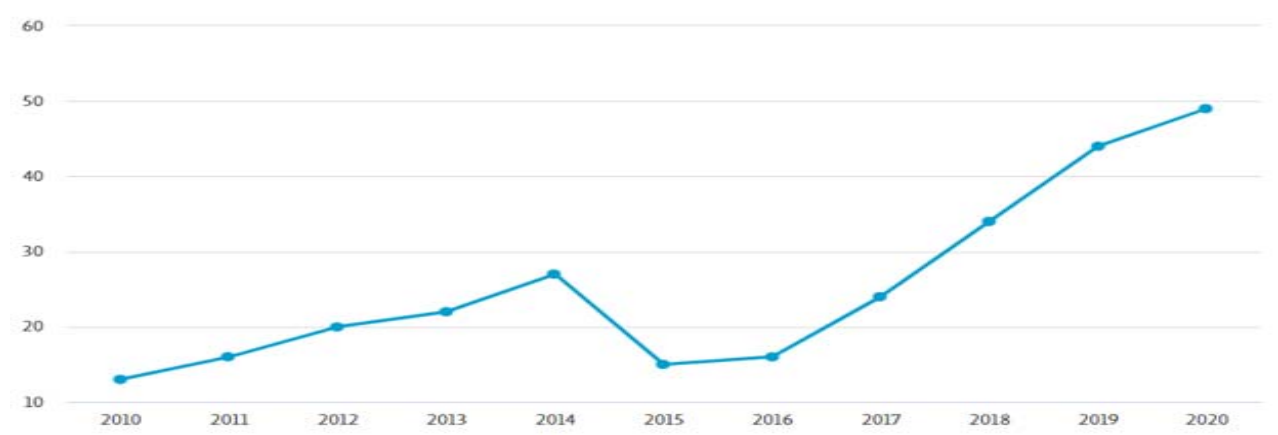

Fig. 1. The frequency of the authors' use of the term of "joint consumption" in publications indexed in the Scopus Elsevier database between 2010 and 2020 (sampling by words "joint consumption").

Source: https://scopus.com//term/analyzer.uri?sid.

Initially, the JCE was considered by economists is a set of economic relations between households (the consumers and providers) through the mediation of companies that development of DOTP as a technological tool for establishing the relationship of these actors [4]. In a society of mass consumption, the emergence of which in the post-war period was stimulated by the marketing strategies of commodity producers, households have accumulated a significant number of not only personal goods and household items (clothes, shoes, toys, accessories, furniture, etc.), but also some cars, vehicles and pieces of real estate. The rational desire of some households to transfer or share these goods or items with other households led to setting up the first models of economic relations between households. The development of DOTP and the widespread use of mobile phones and other gadgets, created the technical conditions for the implementation of these desires of householders. Developing and clarifying this approach, some authors have proposed to consider JCE as platform based collaborative economy (PBCE) [5]. The positive feature of that approach is that the collective nature of transactions within the JCE is emphasized.

As shown in the international bibliographic database Scopus Elsevier, since 2012, the authors began to use the term "sharing economy" more active than the concept of JCE (Fig. 2). 


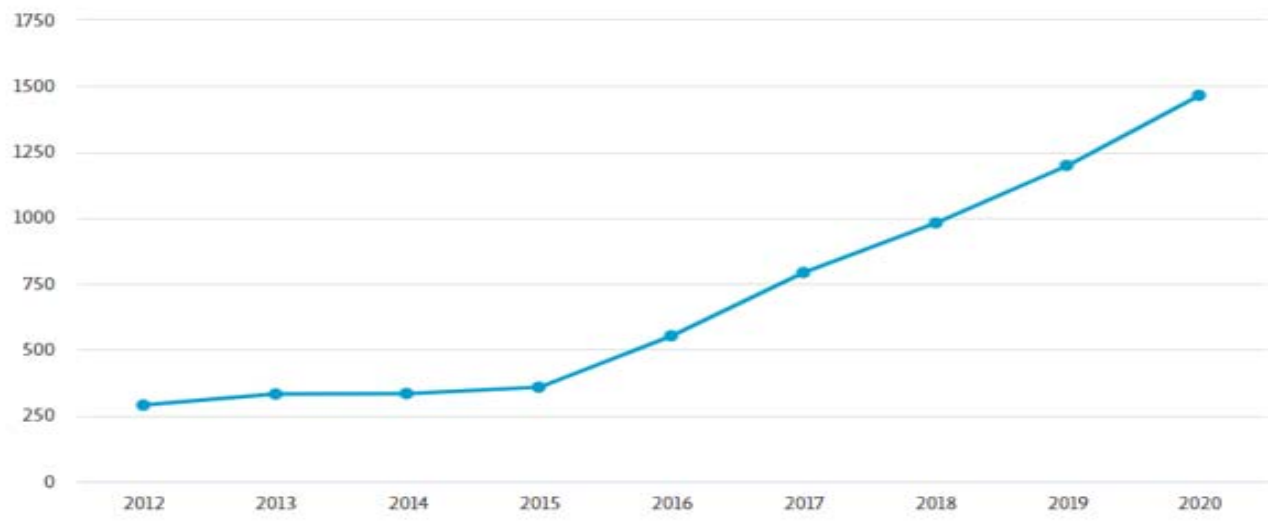

Fig. 2. The frequency of the authors' use of the term of "sharing economy" in publications indexed in the Scopus Elsevier database between 2010 and 2020 (sampling by words "sharing economy").

Source: https://scopus.com//term/analyzer.uri?sid.

Many researchers have investigated the economic meaning of the term "sharing". In the period of 2010 to 2020 as it follows from the data of the world's global citation database Web of Science more than half of all indexed publications that included the word "sharing" were related to economic researches (Fig. 3).

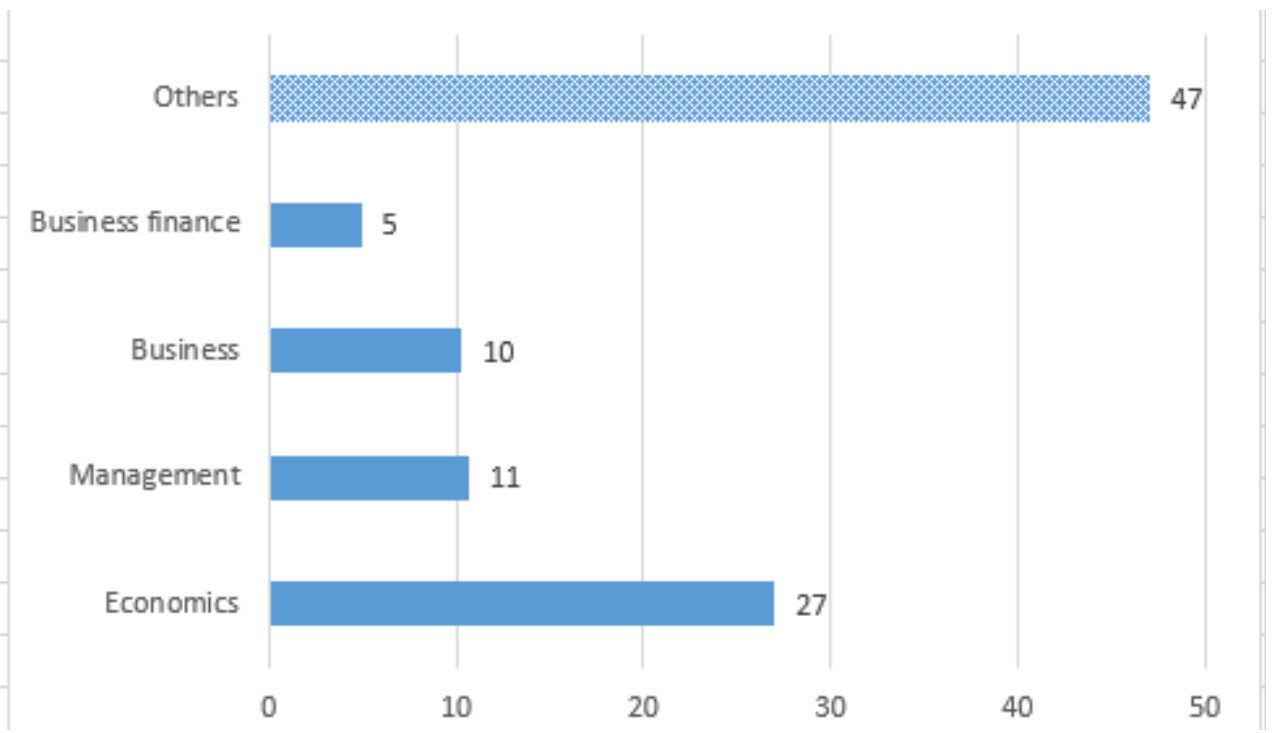

Fig. 3. The frequency of the authors' use of the term of "sharing" in publications indexed in the Web of Science database between 2010 and 2020 (sampling by words "sharing"). Source:

https://apps.webofknowledge.com/WOS_GeneralSearch_input.do.

The economists have provided detailed interpretations of the term "sharing economy" (SE). Judging by the publications indexed in the Scopus Elsevier database, the most active researchers of SE were scientists at Chinese universities, in particular, the oldest Tsinghua University. European, Australian and American researchers have a great interest in that issue (Fig.4). 


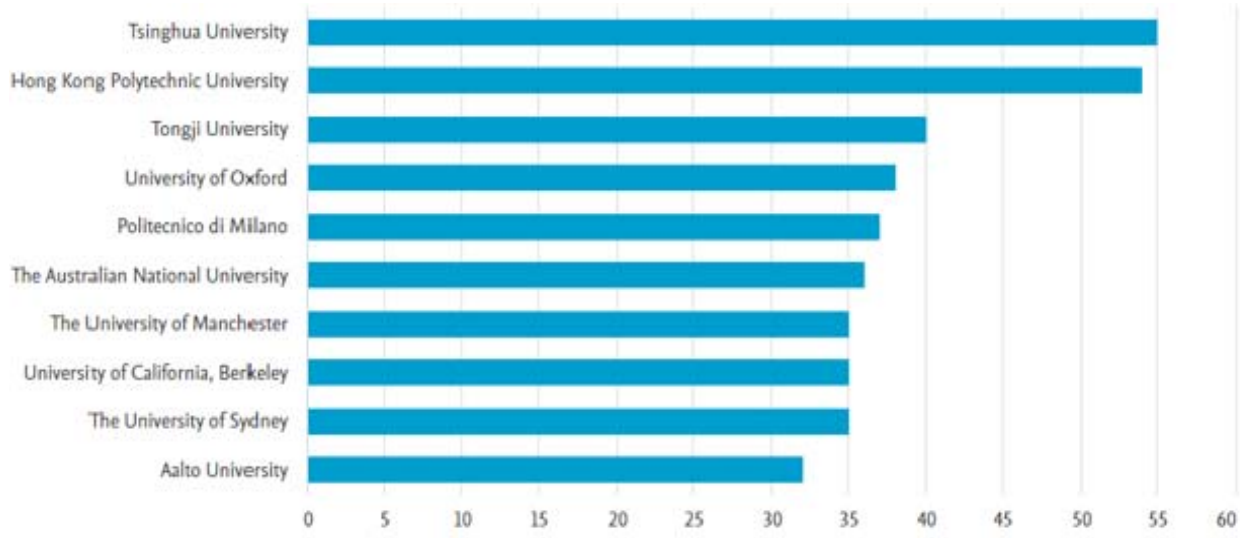

Fig. 4. The frequency of the authors' use of the term of "sharing economy" in publications by authors from different countries indexed in the Scopus Elsevier database between 2010 and 2020 (sampling by words "sharing economy"). Source: https://scopus.com//term/analyzer.uri?sid.

The analysis of the authors' approaches showed a variety of the content of the concept of SE and the ratio of SE and JCE. Summing up the points of view of researchers, several conceptual approaches have to be identified. First approach adopts the main initial idea that $\mathrm{SE}$ is a social process among private persons (P2P) without payment ("sharing for free" or "philanthropic sharing") [6,7]. According to another more common nowadays, approach researchers focused on the hypothesis that SE is the specific commercial activity or a new type of business model $[8,9]$. In the same time an extended interpretation of the term of SE were framed and its original sense was changed. Now significant attention of researchers focuses on the definition of types of business models based on DOTP [10-12]

Various interpretations of the SE and JCE are indicated the relevance of continuing the study of these important parts of the modern economy. In addition, it must be taken into account that modern scientific literature does not reflect the possibilities of JCE for finding new sources of material, human and financial resources to increase the competitiveness of the agricultural sector of the economy. The paper presents the intermediate results of the study of the processes of the setting up and development of the models of JCE in agroindustrial sector.

\section{The methods of the study and data source}

Various methods of study were used including literature analysis, content analysis, generalization, graphic methods, comparison, review and interpretation. Empirical material compiled statistical data from official and reliable sources. A survey of 18 farmers was conducted in 2020 remotely in the Moscow region (Russia). The important data source for analysis was the information on the publications posted by authors in the international database of Scopus and Web of Science between 2010 and 2020.

\section{Results and discussion}

The above analysis showed that the models that some authors identified as the JCE include at least several types of peer-to-peer (P2P) models i.e. relations among private persons. First of all, a donating model of some types of the unused or superfluous consumer goods on a free of charge basis. Second, the barter model when households exchanged with each other some goods or items without discussing the equivalence of the exchange when 
households exchanged some goods or items. Third, the model of selling these goods and items for a price that is lower than the market price. Fourth, the model of temporary use for money of such expensive goods as household items (household appliances) and bikes, cars, vehicles, apartments, houses. Fifth, the model of temporary use of the above expensive items on a free of charge basis. In the models under consideration, the word "Goods" means not only not only physical assets but also services.

In our opinion "donating model", "barter model" and "selling model" refers to traditional models of the relationship between households based on the alienation of private goods and items for payment or without payment. These three models do not belong to models of JCE, despite the fact that these are models of «people-to-people» through DOTP. Only the last two models can be assigned to models of JCE, since these models are based on temporary access or use of goods without transfer of ownership to the consumers.

The peculiarity of the agro-industrial sector is that one of the main "economic operating unit" is a farming. A farm is considered as an individual household that carries out the production and other economic activities (production, processing, storage, transportation and sale of agricultural products) based on the personal participation of household's members. Farmers fulfill the entrepreneurial activities without forming a legal entity based on civil legislation. That feature implies the fact that in the agro-industrial sector, farms can use the advantages of the models of JCE in the presence of DOTP, including the specialized DOTP for the needs of agricultural producers.

The objects of transactions of the models of JCE used by farmers are the production assets (tractors, combines, seeders, trucks and other equipment). Naturally, one of the first models of JCE was the "agro-car sharing" including joint consumption of any agricultural machinery or equipment. Another model of JCE can be attributed the "warehouse sharing" like a flat-sharing. Besides in JCE services are offered, in a similar way as assets, from peers to peers. In addition to China,these models of JCE have widespread in Asian countries with agricultural economies and a predominance of smallholders (Indonesia, Philippines, Thailand). Now the most popular model of JCE is the crowdfunding[13,14]. Thanks to financial model farmers receive the additional funding to ensure the financial stability of their farms.

\section{Conclusion}

The development of the models of JCE directly depends on the level of digitalization of countries, digital literacy, and the availability of specialized DOTP for farmers. The rapid implementation of the models of JCE in the agro-industrial sector of a number of countries is explained by the collective and collaborative traditions of the farming.

The reviewed models of JCE are based on direct mutually beneficial economic relations between farms through the Internet platforms. These collaborative models are a small part of the models of SE. With the development of digitalization and commercialization in most business models of SE, specialized commercial companies are becoming a party that generates the supply of services and resources for farms. As it is noted by the foreign authors, the various options of the models of B2C (Business-to-Customer) began to prevail [15]. At the same time, a survey of Russian farmers have shown their considerable interest in the development of the models of JCE. About $95 \%$ of the surveyed farmers noted the advantage of the models of JCE and the high cost of the models of B2C.

The study shows that in the Russian agro-industrial sector there are certain reserves for increasing its efficiency and competitiveness while creating favorable conditions by State for the continuation of the implementation of the models of JCE in the near future. The definition of these conditions should become the object of further research, as well as the choice of the most appropriate business models for the domestic agro-industrial sector. 
The study was carried out with the financial support of the Russian Foundation for Basic Research within the framework of scientific project No. 20-010-00180 "a".

\section{References}

1. E. Platonova, O. Fedotova and V.Latun, E3S Web of Conference, 210 (2020), doi:10.1051/e3sconf/202021013006

2. H. Heinrichs, GAIA, 22(4), 228-231 (2013), doi: 10.14512/gaia.22.4.5

3. R. Botsman, and R.Rogers, What's Mine is Yours: The Rise of Collaborative Consumption (Tantor Audio; Unabridged CD edition, 2010)

4. T. Ignatova, E. Platonova, A. Pavlyukova, and G. Sroslak, Advances in Economics, Business and Management Research Proceedings, 139 (2020), doi:10.2991/aebmr.k.200509.063

5. K. Stanoevska-Slabeva, V. Lenz-Kesekamp, and V. Suter, Platforms and the Sharing Economy (2020)

6. N.A.John, The age of sharing (2017), doi: 10.1177/2050157917735735

7. R. Belk, Journal of Business Research, 67(8), 1596-1600 (2014), doi: 10.1016/j.jbusres.2013.10.001

8. B. Cohen, and J. Kietzmann, Organization \& Environment, 27(3), 279-296 (2014)

9. A. Stephany, The Business of Sharing: Making it in the New Sharing Economy (2015), doi: $10.1057 / 9781137376183$

10. P. Muñoza, and B. Cohen, Technological Forecasting and Social Change, 125, 21-37 (2017), doi:10.1016/j.techfore.2017.03.035

11. C. M. Barbu, R. S. Bratu, E. M. Sirbu, Review of International Comparative Management, 19(2), (2018), doi: 10.24818/RMCI.2018.2.154

12. S. K. Curtis, and O Mont, Journal of Cleaner Production, 266 (2020), doi.org/10.1016/j.jclepro.2020.121519

13. A. Nabradi, T.Z. Kovacs, WBJAERD, 2(1), 2-19 (2020), doi: 10.5937/WBJAE2001009N

14. A. Nabradi, T.Z. Kovacs, Oradea Journal of Business and Economy, 5(1), 60-71 (2020)

15. A. Acquier, T. Daudigeos, J. Pinkse, Technological Forecasting and Social Change, 125, 1-10 (2017), doi: 10.1016/j.techfore.2017.07.006 